\title{
Avaliação de perdas em uma colhedora de fluxo axial para feijão ${ }^{1}$
}

\author{
Cristiano M. A. de Souza² ${ }^{\text {, Daniel M. de Queiroz }}{ }^{3}$, Paulo R. Cecon ${ }^{4}$ \& Evandro C. Mantovani ${ }^{5}$
}

\begin{abstract}
1 Parte da Dissertação de Mestrado do primeiro autor, apresentada à Universidade Federal de Viçosa
2 DEA/UFV, CEP 36571-000, Viçosa, MG. Fone: (31) 3899 2853. E-mail: csouza@alunos.ufv.br (Foto)

3 DEA/UFV, CEP 36571-000, Viçosa, MG. Fone: (31) 3899-1882. E-mail: queiroz@mail.ufv.br

4 DPI/UFV, CEP 36571-000, Viçosa, MG. Fone: (31) 3899-1781. E-mail: cecon@dpi.ufv.br

${ }^{5}$ Embrapa Milho e Sorgo, CEP 35701-970, Sete Lagoas, MG. Fone: (31) 3779-1105. E-mail: evandro@cnpms.embrapa.br
\end{abstract}

Protocolo $106-3 / 7 / 2001$

\begin{abstract}
Resumo: Na avaliação de máquinas de colheita é importante a determinação da capacidade de processamento e das perdas ocorridas no processo, razão pela qual este trabalho teve por objetivo avaliar as perdas e a capacidade de colheita de uma colhedora de arrasto de fluxo axial, na colheita de feijão. Testes de campo foram realizados sob diferentes condições de trabalho. A partir dos dados obtidos, pode-se concluir que a maior perda ocorreu na plataforma de recolhimento, representando $49,30 \%$ da perda total da colhedora, enquanto as perdas no sistema de trilha e separação e de limpeza foram de 43,61 e 7,09\%, respectivamente. A capacidade de colheita máxima atingida pela máquina foi de $6,56 \mathrm{t} \mathrm{h}^{-1}$.
\end{abstract}

Palavras-chave: colheita, desempenho, colhedora de arrasto

\section{Evaluation of losses in an axial flow bean harvester}

\begin{abstract}
The evaluation performance of a harvester should include the energy needed for its operation, the harvesting capacity and the quantitative loss in the process. The objective of this work was to evaluate the performance of a bean harvester. Field tests were done in different operational conditions. Based on the collected data, it was concluded that the harvester header causes the greatest quantitative loss, responsible for $49.30 \%$ of the total loss. In the separation and cleaning systems the losses were 43.61 and $7.09 \%$, respectively. The maximum harvesting capacity of the machine was $6.56 \mathrm{t} \mathrm{h}^{-1}$ of grains.
\end{abstract}

Key words: harvesting, performance, pull-type harvester

\section{INTRODUÇ̃̃O}

Dentre as etapas do ciclo operacional de uma cultura, normalmente a colheita se destaca em razão das dificuldades e dos altos custos envolvidos, seja ela realizada de forma manual ou mecanizada. Na cultura do feijão, essas dificuldades são ainda maiores pois, devido às suas características botânicas, há mais facilidade de deiscência das vagens, ocasionada pelo estádio de desenvolvimento e condições da cultura, e pela manipulação realizada por máquinas, além de se tratar de uma cultura com tendência a acamar, dificultando sua colheita por colhedoras convencionais, para a colheita de grãos.

A colheita do feijão pode ser feita manual, mecanicamente ou por uma combinação de ambas (Silva \& Queiroz, 1998). A colheita, utilizando-se a combinação manual e mecânica, é realizada com pelo menos três operações de campo, em um período de 2 a 12 dias, pois consiste em arrancar as plantas inteiras quando estas se encontram quase desprovidas de folhas e os grãos com baixo teor de umidade. Com as plantas arrancadas, são formadas leiras que permanecem na lavoura para completar o processo de secagem e homogeneização natural (Conto et al., 1980) e, por fim, uma operação na qual uma máquina colhedora de grãos, convencional ou específica para feijão, recolhe o produto e separa os grãos do resto da planta (Smith, 1986); entretanto, algumas peculiaridades relacionadas à interação máquina-planta durante este processo, têm provocado elevada perda de produto.

Silva et al. (1994) quantificando as perdas na plataforma segadora de colhedora autopropelida de feijão, em diferentes regiões brasileiras, verificaram valores entre 3,93 e 61,19\%. Nave et al. (1972) e Dunn et al. (1973) observaram perdas na plataforma segadora de $80 \%$; portanto, foi ressaltada a necessidade de se continuar o estudo, visando reduzir as perdas, por meio de melhoria do sistema de recolhimento.

Smith (1986) estudou as perdas ocorridas em cada etapa do processo de colheita mecânica do feijão, mostrando que elas variaram de 1 a $13 \%$, com média de $3,7 \%$, sendo que $20 \%$ das perdas ocorreram no corte (arranquio) feito com ceifador, $20 \%$ 
no enleiramento e $60 \%$ nas etapas de recolhimento, trilha e separação. Mesquita et al. (1998) estudando as perdas na colheita de soja, mostraram que é possível diminuí-las significativamente, visto que ocorreram reduções de $69 \%$ no Paraná e 37\% nos demais estados produtores.

Verifica-se, portanto, que no nível tecnológico atual existe ainda um bom potencial de ganho com a utilização de mecanismos dimensionados adequadamente com melhores recursos de síntese, análise e otimização. Este potencial deve ser concentrado na área de colheita de grãos com maiores perdas, como soja e feijão (Contreras, 1997). Portella (1997) sugere, como meios para reduzir as perdas, o desenvolvimento de metodologias para regulagem de colhedoras, assim como o uso de novos mecanismos que potencializem o desempenho da máquina.

Este trabalho foi desenvolvido com o objetivo de se avaliar os efeitos da taxa de alimentação, obtidas pela variação do número de linhas de feijão na leira e da velocidade de trabalho da máquina, da rotação do cilindro trilhador e do teor de umidade sobre as perdas em diferentes sistemas de uma colhedora de arrasto e de fluxo axial.

\section{MATERIAL E MÉTODOS}

O trabalho foi conduzido no Campo Experimental e no Laboratório de Automação Agropecuária da Embrapa Milho e Sorgo e no Laboratório de Mecanização Agrícola do Departamento de Engenharia Agrícola da Universidade Federal de Viçosa, com a colaboração das empresas MIAC, COTRAME e AEMCO das Indústrias Reunidas Colombo Ltda.

Nos ensaios, utilizou-se o feijão (Phaseolus vulgaris L.), cultivar Carioca, sendo a máquina avaliada uma colhedora de arrasto modelo "Double Master" (Figura 1) com sistema de trilha em fluxo axial. A máquina foi tracionada e acionada por um trator Massey-Ferguson, Modelo MF 620, com potência nominal de $82 \mathrm{~kW}$.

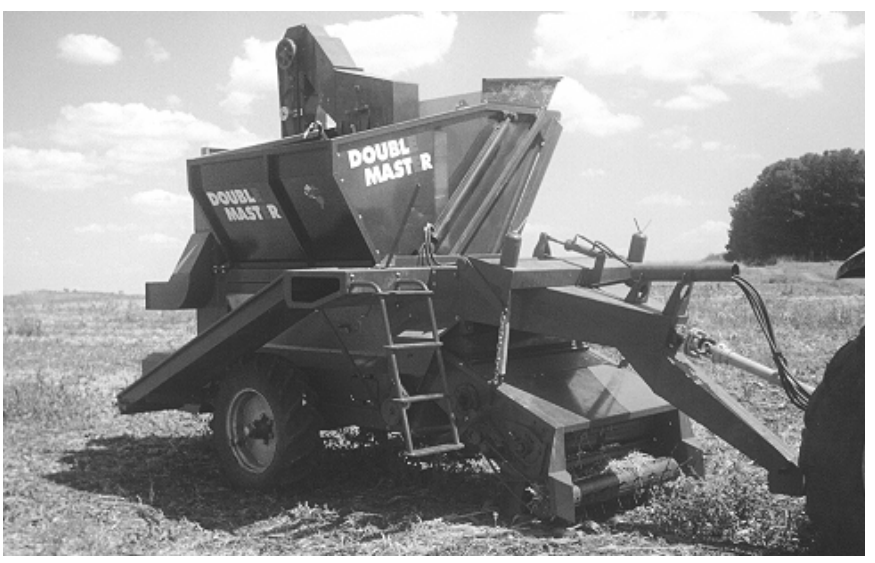

Figura 1. Colhedora modelo "Double Master"

As variáveis investigadas nos ensaios, foram: taxas de alimentação da máquina, obtidas pela variação do número de linhas de feijão na leira (4, 7 e 10 linhas) e da velocidade de trabalho da máquina $\left(4,7\right.$ e $\left.10 \mathrm{~km} \mathrm{~h}^{-1}\right)$, e rotações do cilindro trilhador ( 420 e 540 rotações min $^{-1}$ ). A abertura entre cilindro e côncavo foi $20 \mathrm{~mm}$. Montou-se um experimento em esquema fatorial $3 \times 3$ × 2, com três constituições de leira, três velocidades de deslocamento e duas rotações do cilindro trilhador, instalado segundo o delineamento inteiramente casualizado, com duas repetições. Os dados obtidos foram submetidos à análise de variância e de metodologia de superfície de resposta. Os modelos foram escolhidos com base na significância dos coeficientes de regressão, utilizando-se o teste $\mathrm{t}$ a $10 \%$ e o coeficiente de determinação. A análise estatística dos dados foi realizada utilizando-se o programa computacional SAEG, versão 8 .

Em cada teste foram determinados a velocidade de deslocamento da máquina, a massa de grãos colhidos e o tempo necessário para colhê-la, o teor de umidade dos grãos e a massa de grãos perdida.

Nas avaliações, foram consideradas duas faixas de teores de umidade de colheita, sendo uma de 10,65 $\pm 0,25$ e outra de $14,10 \pm 0,81 \%$ b.u. Buscando-se minimizar o desvio entre os valores de teor de umidade de colheita, os testes foram conduzidos em dois pivôs centrais.

Antes de se iniciar a colheita com a máquina, realizaram-se medições em diferentes locais da área, a fim de determinar a perda natural, totalizando 10 amostras por leira. Uma armação de 2,0 $\mathrm{m}^{2}$ foi colocada no sentido transversal ao plantio das linhas, conforme metodologia da Embrapa Arroz e Feijão. Os grãos soltos e aqueles contidos nas vagens encontradas no chão dentro da armação, foram pesados. A perda natural foi obtida do quociente da massa de grãos perdidos pela área da armação, como se segue.

$$
\mathrm{P}_{\mathrm{n}}=10 \frac{\mathrm{m}_{\mathrm{n}}}{\mathrm{A}}
$$

em que:

$P_{n} \quad$ - perda natural, $\mathrm{kg} \mathrm{ha}^{-1}$

$\mathrm{m}_{\mathrm{n}}$ - massa de grãos perdidos naturalmente, na área da armação, $g$

A - área da armação, $\mathrm{m}^{2}$

As plantas foram arrancadas quando suas folhas iam ficando amareladas e as vagens mais velhas começavam a secar, conforme Silva \& Bevitori (1994); depois, foram determinadas as perdas devidas ao arranquio e enleiramento do feijão. As medições foram feitas em diferentes locais da área, totalizando 10 amostras por leira. A armação de $2,0 \mathrm{~m}^{2}$ foi colocada no sentido transversal ao plantio das linhas. Os grãos soltos e os encontrados nas vagens dentro da armação foram pesados. O valor da perda no arranquio e enleiramento foram obtidos da mesma forma que para a perda natural, descontando-se os valores desta, conforme apresentado a seguir.

$$
\mathrm{P}_{\mathrm{a}}=10 \frac{\mathrm{m}_{\mathrm{a}}}{\mathrm{A}}-\mathrm{P}_{\mathrm{n}}
$$

em que:

$\mathrm{P}_{\mathrm{a}} \quad$ - perda no arranquio e enleiramento, $\mathrm{kg} \mathrm{ha}^{-1}$

$\mathrm{m}_{\mathrm{a}}$ - massa de grãos perdidos após o arranquio e enleiramento, na área da armação, $g$ 
Ao final de cada teste com a colhedora, determinaram-se as perdas na plataforma de recolhimento, no sistema de trilha e separação e de limpeza da máquina. Após a colheita do equivalente a $100 \mathrm{~m}$ de leira, a operação da máquina foi interrompida e as perdas na plataforma de recolhimento foram avaliadas. Deu-se marcha-a-ré na colhedora, a uma distância igual à metade de seu comprimento. A armação de $2,0 \mathrm{~m}^{2}$ foi disposta na parte colhida em frente à colhedora, coletando-se todos os grãos ali presentes, soltos ou nas vagens. A perda na plataforma de recolhimento foi obtida subtraindo-se, do total, a perda natural e no arranquio e enleiramento, como mostra a seguinte expressão:

$$
P_{r}=10 \frac{m_{r}}{A}-P_{n}-P_{a}
$$

em que:

$\mathrm{P}_{\mathrm{r}} \quad$ - perda na plataforma de recolhimento, $\mathrm{kg} \mathrm{ha}^{-1}$

$\mathrm{m}_{\mathrm{r}}$ - massa de grãos perdidos embaixo da plataforma de recolhimento, na área da armação, g

Na determinação da perda no sistema de separação, a armação de 2,0 $\mathrm{m}^{2}$ foi colocada lateralmente à colhedora, uma vez que a descarga de material desse sistema é feita no lado esquerdo da máquina. As perdas no sistema de separação foram calculadas subtraindo-lhes a perda natural e a perda no arranquio e enleiramento.

$$
\mathrm{P}_{\mathrm{s}}=10 \frac{\mathrm{m}_{\mathrm{s}}}{\mathrm{A}}-\mathrm{P}_{\mathrm{n}}-\mathrm{P}_{\mathrm{a}}
$$

em que:

$\mathrm{P}_{\mathrm{s}} \quad$ - perda no sistema de separação, $\mathrm{kg} \mathrm{ha}^{-1}$

$\mathrm{m}_{\mathrm{s}}$ - massa de grãos perdidos na lateral da máquina colhedora, na área da armação, g

Para se determinar os grãos perdidos no sistema de limpeza, a armação foi disposta atrás da colhedora e as perdas ocorridas neste sistema foram calculadas subtraindo-lhes a perda natural, no arranquio e enleiramento e no recolhimento.

$$
\mathrm{P}_{1}=10 \frac{\mathrm{m}_{1}}{\mathrm{~A}}-\mathrm{P}_{\mathrm{n}}-\mathrm{P}_{\mathrm{a}}-\mathrm{P}_{\mathrm{r}}
$$

em que:

$\mathrm{P}_{1} \quad$ - perda no sistema de limpeza, $\mathrm{kg} \mathrm{ha}^{-1}$

$\mathrm{m}_{1} \quad$ - massa de grãos perdidos após a passagem da máquina colhedora, na área da armação, g

Finalmente, foi determinada a perda total da colhedora, obtida somando-se as perdas na plataforma de recolhimento com as perdas do sistema de separação e as perdas do sistema de limpeza, como apresentado a seguir.

$$
P_{t}=P_{r}+P_{s}+P_{1}
$$

em que:

$\mathrm{P}_{\mathrm{t}} \quad$ - perda total da colhedora, $\mathrm{kg} \mathrm{ha} \mathrm{h}^{-1}$
Em todos os testes de campo, o teor de umidade dos grãos perdidos pela máquina foi considerado igual ao teor de umidade dos grãos contidos no tanque graneleiro da colhedora.

Para se determinar a capacidade de colheita, a máquina foi colocada para colher numa distância conhecida, cronometrando-se o tempo gasto por ela nesse percurso e, em seguida, pesando-se o produto colhido. A capacidade de colheita foi obtida da relação entre a massa de grãos colhidos e o tempo gasto no percurso, conforme observado na Eq. 7. Para garantir que um teste não influenciasse o próximo, a máquina foi totalmente limpa de grãos e palhada ao final de cada teste.

$$
\mathrm{C}_{\mathrm{c}}=3,6 \frac{\mathrm{m}_{\mathrm{g}}}{\mathrm{t}}
$$

em que:

$\mathrm{C}_{\mathrm{c}} \quad$ - capacidade de colheita, $\mathrm{t} \mathrm{h}^{-1}$

$\mathrm{m}_{\mathrm{g}} \quad$ - massa de grãos colhidos, $\mathrm{kg}$

$\mathrm{t} \quad$ - tempo gasto para colher $\mathrm{m}_{\mathrm{g}}, \mathrm{s}$

O valor de massa de grãos colhida ou perdida foi corrigido para $11 \%$ de teor de umidade final do produto.

\section{RESULTADOS E DISCUSSÃO}

Em trabalho de colheita de culturas com tendência a fácil deiscência das vagens, como é o caso do feijão, tem-se observado grande perda de produto no ato do corte e do recolhimento das plantas no campo. A perda natural e aquelas verificadas no arranquio e enleiramento manual somadas, não foram significativas, pois não ultrapassaram $0,1 \%$, razão pela qual elas foram desprezadas.

Para se estudar o comportamento da perda na plataforma de recolhimento da colhedora em função do número de linhas de feijão na leira, da velocidade de deslocamento e rotação do cilindro trilhador da máquina, foram feitos cortes nos modelos de superfície de resposta ajustados, conforme Figuras 2, 3 e 4, nas quais, analisando-se os dados obtidos, verifica-se que a perda na plataforma diminuiu com o aumento do número de linhas na leira, mas cresceu na medida em que ocorre aumento na velocidade de deslocamento e na rotação do cilindro trilhador da máquina. Na colheita do produto com $10,65 \%$ de teor de umidade, apesar da rotação não ser significativa, observou-se o mesmo comportamento de perda na plataforma que com $14,10 \%$ de teor de umidade. O mesmo aconteceu para o número de linhas na leira e teor de umidade de $14,10 \%$. As leiras constituídas de 10 linhas e a velocidade de deslocamento de $4,0 \mathrm{~km} \mathrm{~h}^{-1}$, constituem as condições de trabalho que levaram aos menores valores de perda na plataforma.

O acréscimo da perda na plataforma, resultante do incremento na velocidade de deslocamento da máquina, pode ser explicado pelo fato da rotação do recolhedor ser função direta da rotação do cilindro trilhador, e não função do deslocamento da máquina; isto fez com que o recolhedor empurrasse a leira para a frente, formando um amontoado que, quando recolhido o material, era pressionado pela esteira elevadora contra a base da plataforma provocando, então, a deiscência das vagens mais secas. As leiras com maior número 


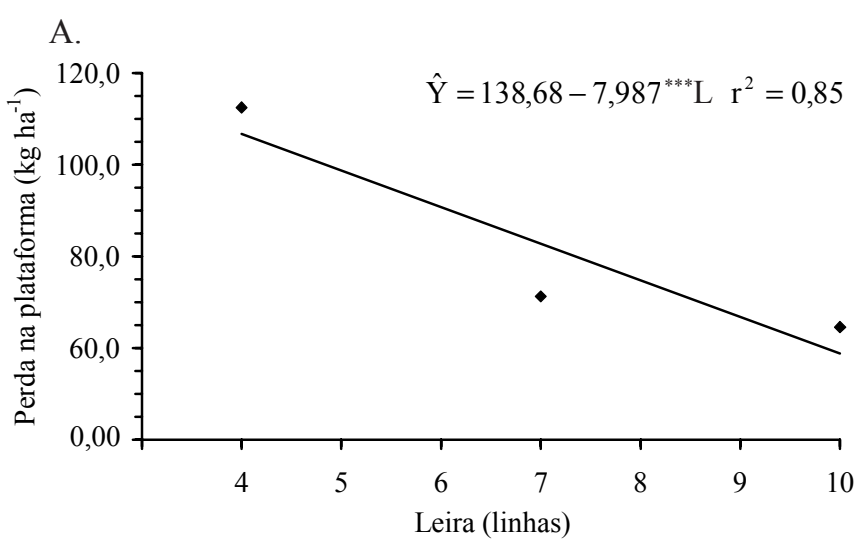

B.

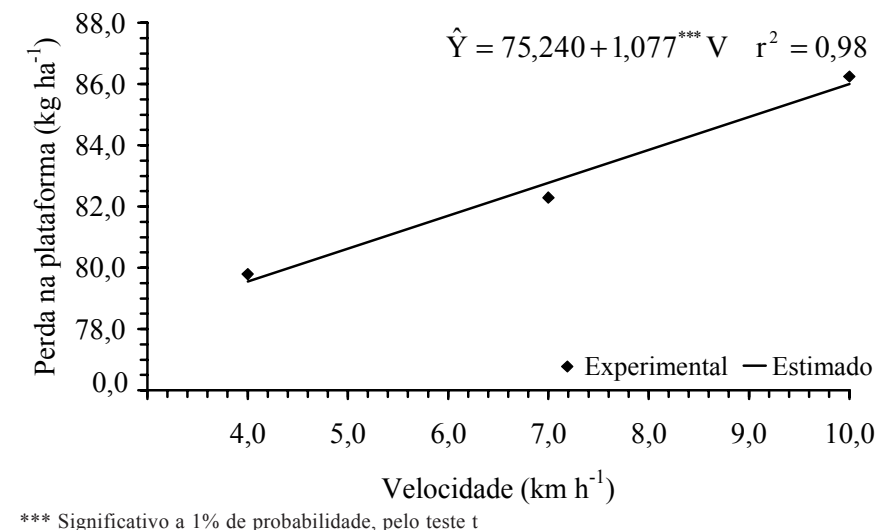

Figura 2. Estimativa da perda na plataforma de recolhimento, em função do número de linhas de feijão na leira, para a rotação do cilindro trilhador de 420 rotações $\min ^{-1}$ (A), e da velocidade de deslocamento da máquina, para a rotação do cilindro trilhador de 540 rotações $\min ^{-1}$ (B), com teor de umidade de 10,65\%

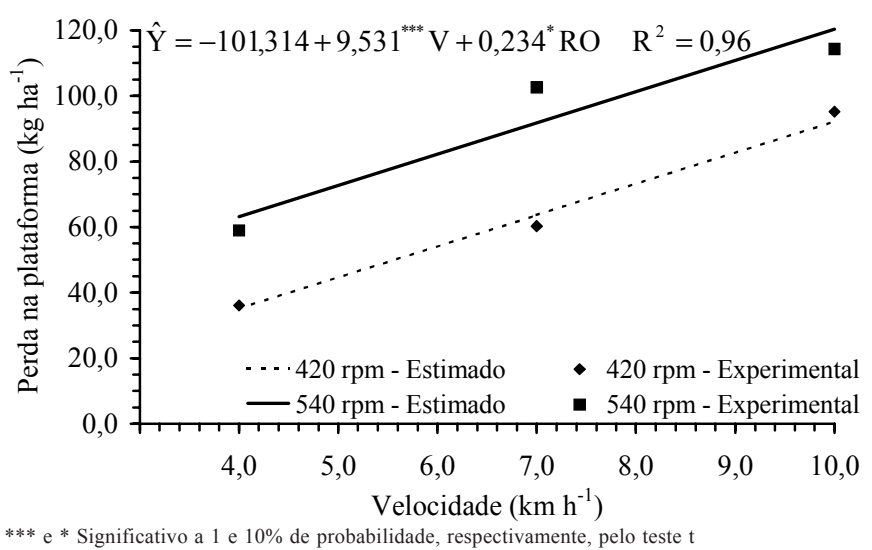

Figura 3. Estimativa da perda na plataforma de recolhimento, em função da velocidade de deslocamento da máquina, para as respectivas rotações do cilindro trilhador, com teor de umidade de $14,10 \%$

de linhas pressionadas pelo elevador da plataforma produziram uma massa mais densa de material, comportando-se como verdadeiras "vassouras", carreando parte dos grãos debulhados no recolhedor ao sistema de trilha e dificultando sua passagem através da palhada.

Os menores valores de perda na plataforma de recolhimento foram observados no experimento com teor de umidade de $14,10 \%$ pois, quanto maior é o teor de umidade, menor é a

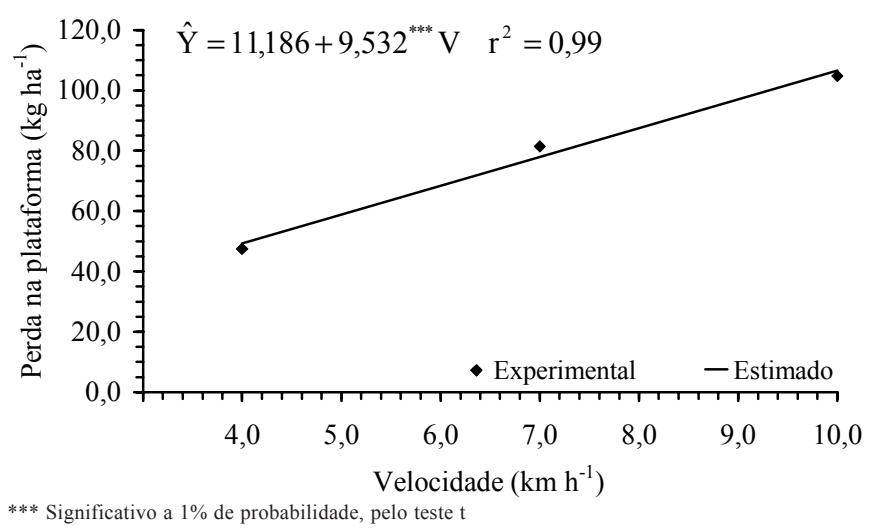

Figura 4. Estimativa da perda na plataforma de recolhimento, em função da velocidade de deslocamento da máquina, com teor de umidade de $14,10 \%$

facilidade de deiscência das vagens. O menor valor de perda foi $35,09 \mathrm{~kg} \mathrm{ha}^{-1}$, obtido para a velocidade de $4 \mathrm{~km} \mathrm{~h}^{-1}$ e rotação do cilindro trilhador de 420 rotações $\mathrm{min}^{-1}$. A produtividade é outro fator que contribuiu para a diferença entre os valores de perda, pois ela tem influência direta na taxa de alimentação da máquina. Na colheita do produto com teor de umidade de $10,65 \%$, observou-se produtividade média de $2238,20 \mathrm{~kg} \mathrm{ha}^{-1}$, enquanto com teor de umidade de $14,10 \%$ a produtividade foi de $2532,35 \mathrm{~kg} \mathrm{ha}^{-1}$.

O sistema de trilha e separação, comum nas máquinas com alimentação em fluxo axial, é o responsável por grande parte das perdas ocasionadas durante a colheita mecânica, em virtude de ser muito influenciado pela taxa de alimentação do sistema, pelo teor de umidade de colheita, pela abertura entre cilindro e côncavo e pela energia transmitida pelo cilindro trilhador.

Para se estudar o desempenho do sistema de trilha e separação da colhedora, em função do número de linhas de feijão na leira, da velocidade de deslocamento e rotação do cilindro trilhador da máquina, foram feitos cortes nos modelos de superfície de resposta ajustados, conforme apresentado nas Figuras 5 e 6 .

Analisando-se os resultados de perda no sistema de trilha e separação, obtidos na colheita do produto com $10,65 \%$ de teor de umidade, verifica-se que a perda decresce com o aumento na velocidade de deslocamento da máquina para um mesmo número de linhas na leira. Para o produto com teor de umidade de $14,10 \%$, a perda cresceu com o aumento na velocidade. Para os testes executados com 540 rotações min $^{-1} \mathrm{e}$ teor de umidade de $14,10 \%$, verifica-se que a perda decresce com o aumento do número de linhas na leira (Figuras 5 e 6). Os menores resultados de perda no sistema de trilha e separação foram observados na colheita do feijão com teor de umidade de $10,65 \%$, obtendo-se valores de 2,48 e 17,74 $\mathrm{kg} \mathrm{ha}^{-1}$, respectivamente, para 420 e 540 rotações min $^{-1}$.

De acordo com os resultados, observa-se que, em geral, o produto com teor de umidade de 10,65\% apresentou menores valores de perda que aquele com teor de umidade de $14,10 \%$, uma vez que, quanto menor o teor de umidade de colheita, maior é a facilidade de debulha das vagens. Resultados semelhantes foram obtidos por Singh \& Singh (1981) e Boller et al. (1998). Outro ponto que pode ter influenciado os valores de perda no sistema de trilha e separação, é a diferença entre a produtividade. 
A.

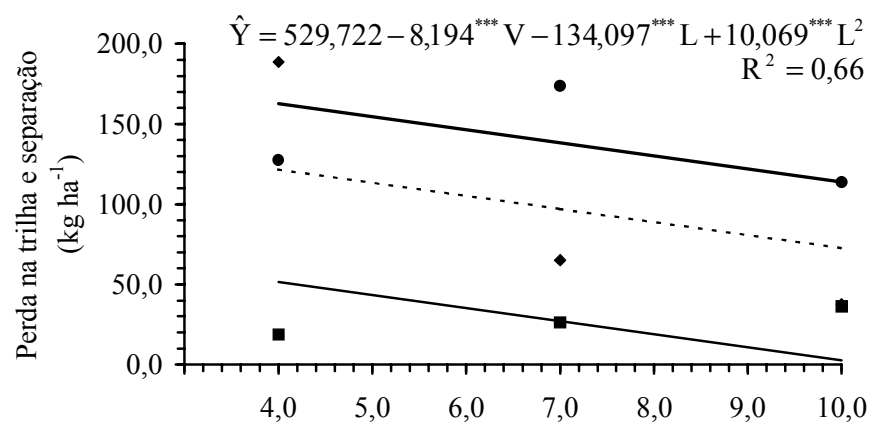

B.

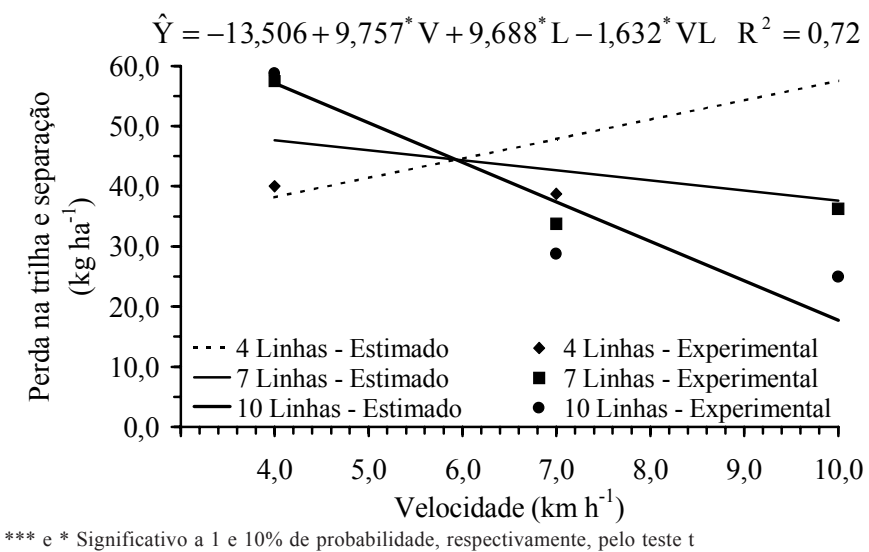

Figura 5. Estimativa da perda no sistema de trilha e separação, em função da velocidade de deslocamento da máquina, para as respectivas constituições de leira, com rotações do cilindro trilhador de 420 (A) e 540 rotações min $^{-1}$ (B) e teor de umidade de $10,65 \%$

Analisando-se os dados médios de perda no sistema de trilha e separação, verifica-se que a rotação de 540 rotações min $^{-1}$ apresentou menores valores de perda que a de 420 rotações min $^{-1}$, o que é atribuído à maior energia transmitida pela primeira (540) às vagens promovendo, assim, melhor separação dos seus grãos.

Para se estudar o desempenho do sistema de limpeza da colhedora, em função do número de linhas de feijão na leira, da velocidade de deslocamento e rotação do cilindro trilhador da máquina, foram feitos cortes nos modelos de superfície de resposta ajustados, conforme apresentado nas Figuras 7 e 8 .

Os dados de perda no sistema de limpeza, em função da velocidade de deslocamento da máquina e do número de linhas de feijão na leira, apresentaram comportamento quadrático de seus valores (Figuras 7 e 8). O produto com teor de umidade de $10,65 \%$ e rotação do cilindro trilhador de 420 rotações min $^{-1}$, apresentou menor valor de perda no sistema de limpeza para a leira de 10 linhas, isto é, $7,65 \mathrm{~kg} \mathrm{ha}^{-1}$; para a rotação de 540 , a leira de 8 linhas apresentou a menor perda, com valor de $6,43 \mathrm{~kg}$ $\mathrm{ha}^{-1}$, não havendo influência da velocidade da máquina. $\mathrm{Na}$ colheita com teor de umidade de $14,10 \%$, na rotação de 420 , a velocidade de $10 \mathrm{~km} \mathrm{~h}^{-1}$ forneceu a menor perda, isto é, $6,46 \mathrm{~kg}$ $\mathrm{ha}^{-1}$, sendo este considerado o melhor resultado porque, nesta velocidade, os valores de capacidade de colheita foram consideravelmente maiores; na rotação de 540 rotações min $^{-1}$, a velocidade de $8,36 \mathrm{~km} \mathrm{~h}^{-1}$ e a leira de 4 linhas apresentaram menor valor de perda, ou seja, $4,87 \mathrm{~kg} \mathrm{ha}^{-1}$.
A.

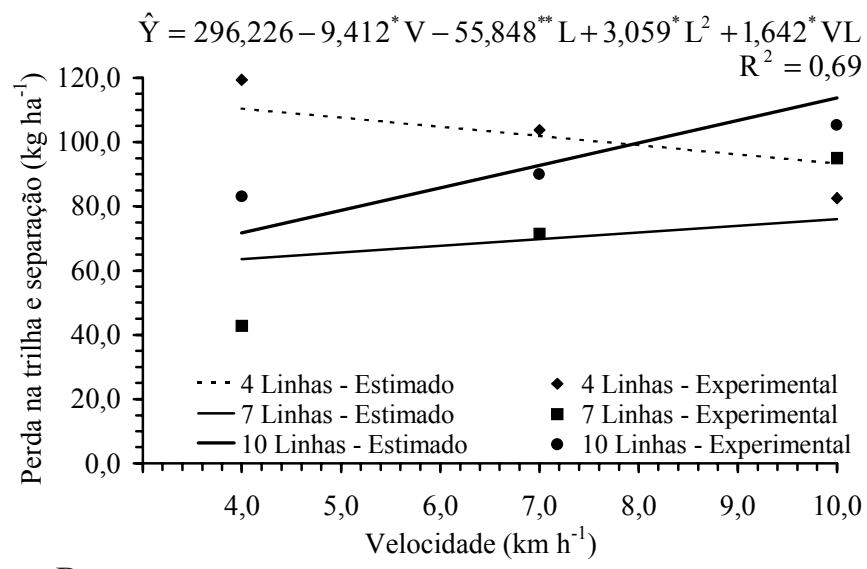

B.

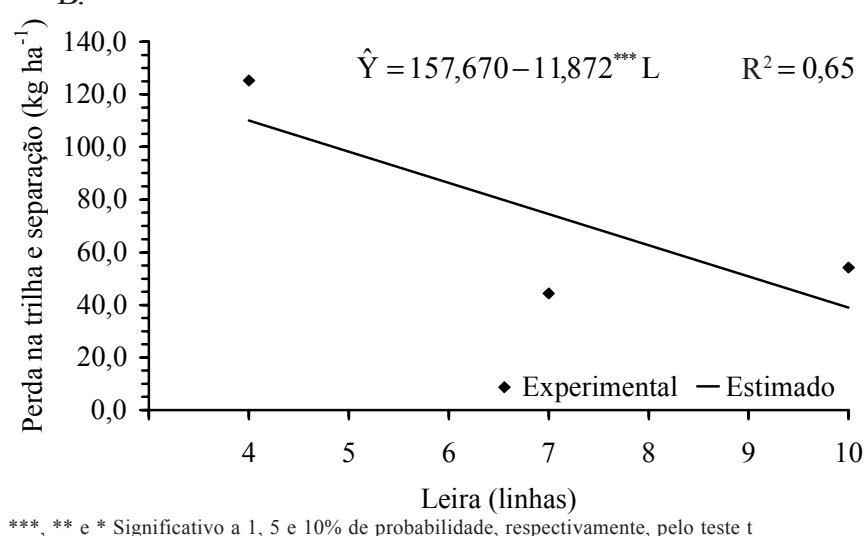

Figura 6. Estimativa da perda no sistema de trilha e separação, em função da velocidade de deslocamento da máquina, para a rotação do cilindro trilhador de 420 rotações $\min ^{-1}$ (A), e do número de linhas na leira, para a rotação do cilindro trilhador de 540 rotações min $^{-1}$ (B), com teor de umidade de $14,10 \%$

A rotação de 420 rotações min $^{-1}$ apresentou menores valores de perda no sistema de limpeza que a rotação de 540 . Da mesma forma, verificou-se diferença de $0,44 \mathrm{~kg} \mathrm{ha}^{-1}(4,31 \%)$ entre as perdas ocorridas nos dois pivôs, não havendo efeito do teor de umidade sobre a perda no sistema de limpeza. Resultados semelhantes foram obtidos por Boller et al. (1998).

O comportamento da perda na limpeza, pode ser explicado pelo fato da rotação do ventilador ser função direta da rotação do cilindro trilhador da colhedora e não função da quantidade de material processado pela máquina. No processo de limpeza, a perda é muito influenciada pelo fluxo de ar do ventilador, pois uma quantidade menor de material passando pelo sistema de limpeza, faz com que o ventilador forneça maior vazão de ar, visto que a resistência à passagem do ar se torna menor; por outro lado, quanto maior for a taxa de alimentação da máquina, maior deve ser o fluxo de ar, sem que este ultrapasse a velocidade terminal dos grãos.

Para se estudar a perda total de grãos da colhedora, em função do número de linhas de feijão na leira, da velocidade de deslocamento e rotação do cilindro trilhador da máquina, foram feitos cortes nos modelos de superfície de resposta ajustados, conforme Figuras 9 e 10.

Analisando-se os resultados de perda total da colhedora obtidos na colheita com teor de umidade de $10,65 \%$, para um 
mesmo número de leiras, verifica-se que, aumentando-se a velocidade de deslocamento da máquina, as perdas diminuíram.

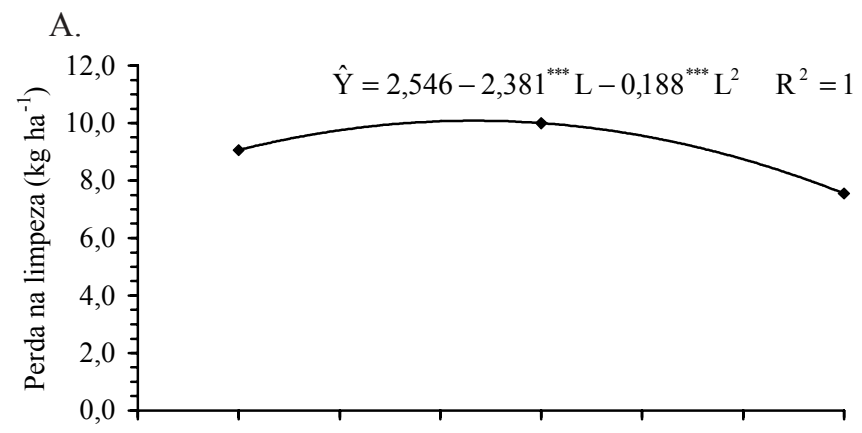

B.

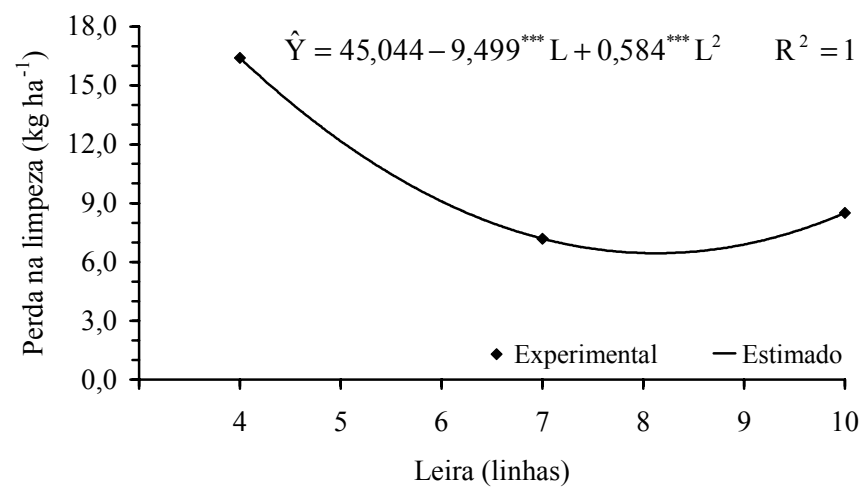

* Significativo a $1 \%$ de probabilidade, pelo teste $\mathrm{t}$

Figura 7. Estimativa da perda no sistema de limpeza, em função do número de linhas na leira, para a rotação de 420 (A) e 540 rotações $\min ^{-1}(\mathrm{~B})$, com teor de umidade de $10,65 \%$
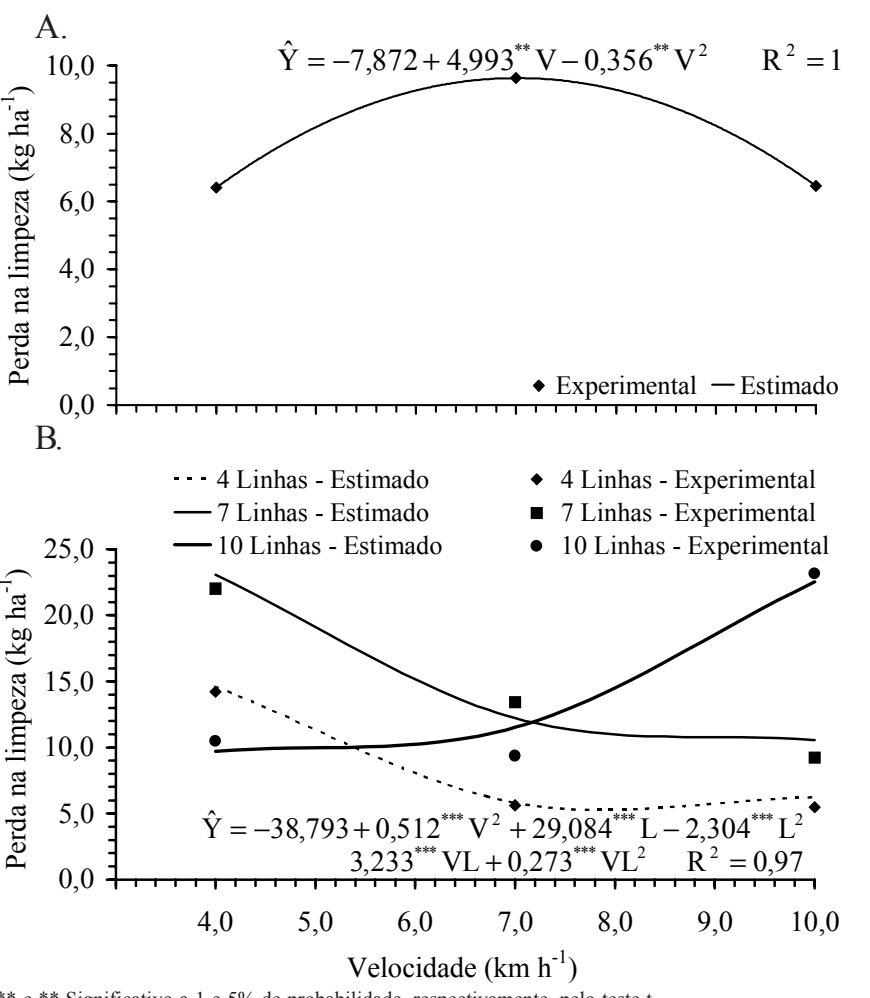

Figura 8. Estimativa da perda no sistema de limpeza, em função da velocidade de deslocamento da máquina, para as rotações do cilindro trilhador de 420 (A) e 540 rotações min $^{-1}$ (B), com teor de umidade de $14,10 \%$
A.
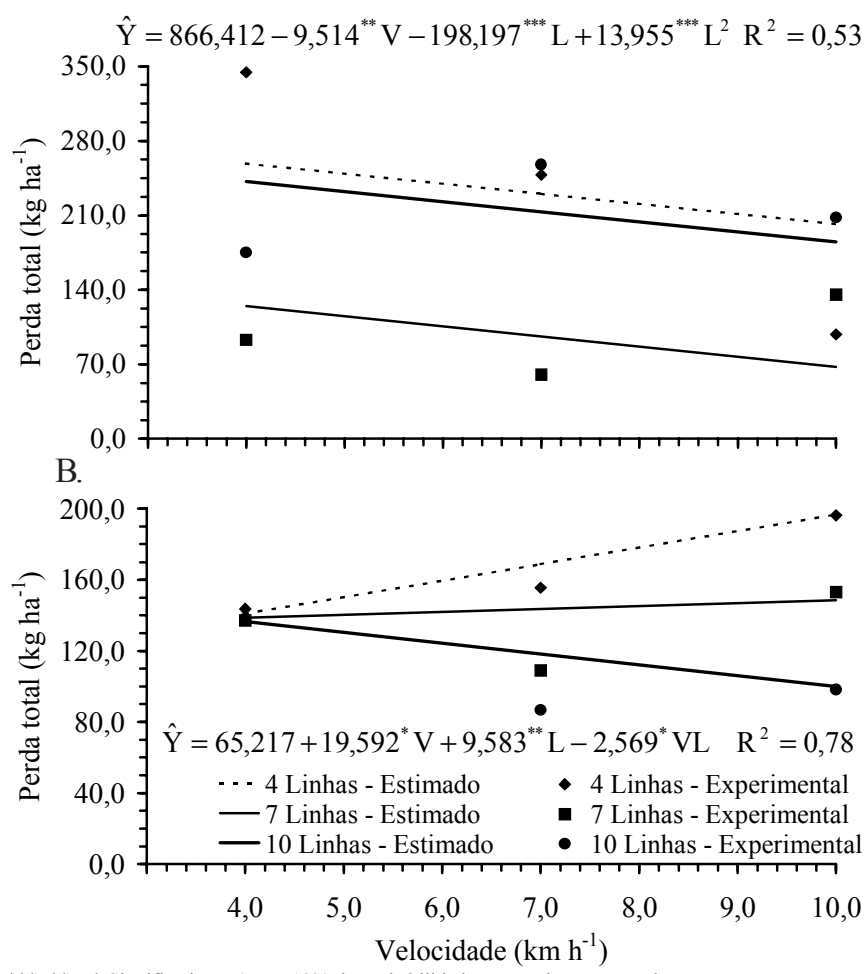

***, ** e * Significativo a 1,5 e $10 \%$ de probabilidade, respectivamente, pelo teste t

Figura 9. Estimativa da perda total da colhedora, em função da velocidade de deslocamento da máquina, para as respectivas constituições de leira, com rotações do cilindro trilhador de 420 (A) e 540 rotações $\min ^{-1}$ (B) e teor de umidade de $10,65 \%$
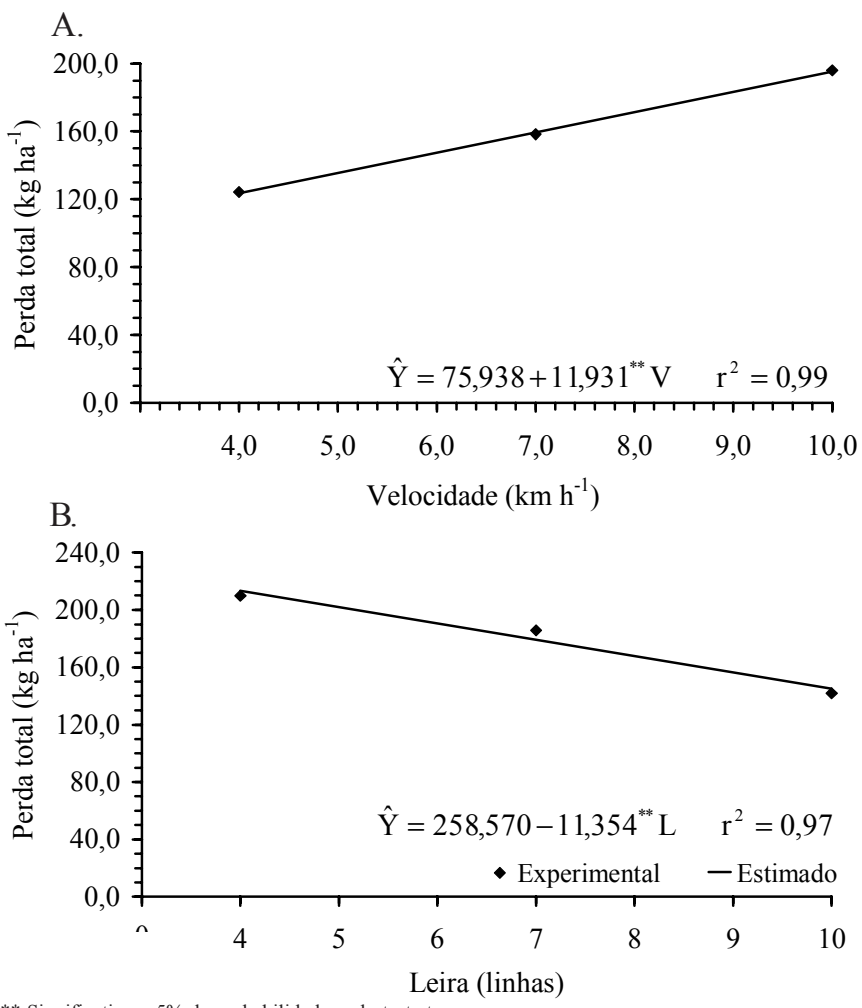

Figura 10. Estimativa da perda total da colhedora em função da velocidade de deslocamento da máquina, para a rotação do cilindro trilhador de 420 rotações $\min ^{-1}$ (A), e do número de linhas na leira, para a rotação do cilindro trilhador de 540 rotações $\min ^{-1}$ (B), com teor de umidade de 14,10\% 
Nos testes efetuados com rotação do cilindro trilhador de 420 rotações $\min ^{-1}$, a menor perda foi apresentada na leira de 7 linhas e velocidade de deslocamento da máquina de $10 \mathrm{~km} \mathrm{~h}^{-1}$, isto é, $67,69 \mathrm{~kg} \mathrm{ha}^{-1}$; por outro lado, na rotação de $540 \mathrm{~min}^{-1}$, a menor perda ocorreu na leira de 10 linhas e velocidade da máquina de $10 \mathrm{~km} \mathrm{~h}^{-1}$, ou seja, 100,07 $\mathrm{kg} \mathrm{ha}^{-1}$.

Nos testes com teor de umidade de $14,10 \%$ e rotação de 420 , a perda total da colhedora aumentou linearmente com o aumento da velocidade de deslocamento da máquina. A perda decresceu com o aumento do número de linha nos testes, na rotação de 540. Nos testes com 420 rotações min $^{-1}$, a velocidade de $4 \mathrm{~km} \mathrm{~h}^{-1}$ apresentou menor valor de perda, atingindo $123,99 \mathrm{~kg} \mathrm{ha}^{-1}$, enquanto para 540 rotações min $^{-1}$ a leira de 10 linhas foi a que proporcionou menor perda, atingindo $145,03 \mathrm{~kg} \mathrm{ha}^{-1}$, enquanto na colheita com teor de umidade de $10,64 \%$, a rotação do cilindro trilhador proporcionou decréscimo nos valores de perda total da colhedora, e com teor de umidade de $14,10 \%$, a tendência foi contrária.

Analisando-se os dados de perda total verifica-se que os testes com teor de umidade de 10,65\% apresentaram menores valores que os testes com teor de umidade de $14,10 \%$. Resultados semelhantes foram obtidos por Singh \& Singh (1981) e Boller et al. (1998).

Os menores valores de perda total da colhedora, para os testes com teor de umidade de $10,65 \%$ e rotação de 420 e 540 $\mathrm{min}^{-1}$, foram 3,02 e $4,47 \%$ do total de produto, respectivamente. Nos testes com teor de umidade de $14,10 \%$, os menores valores de perda para as rotações de 420 e 540 , foram 4,89 e 5,72\%. De acordo com Griffin (1991) esses resultados foram satisfatórios,

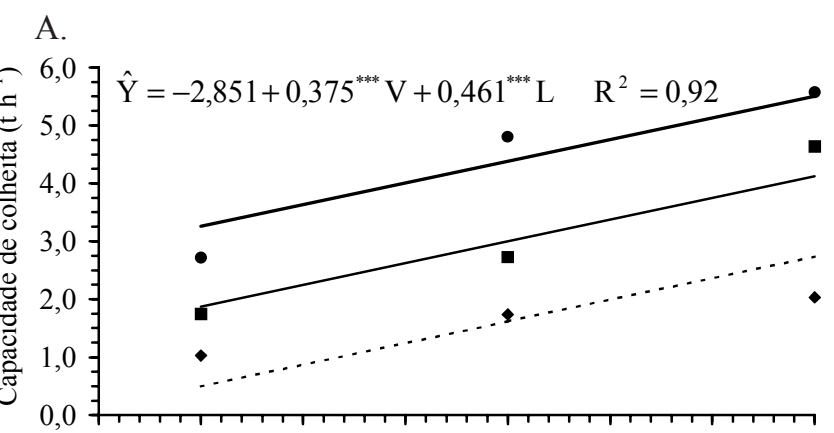

B.

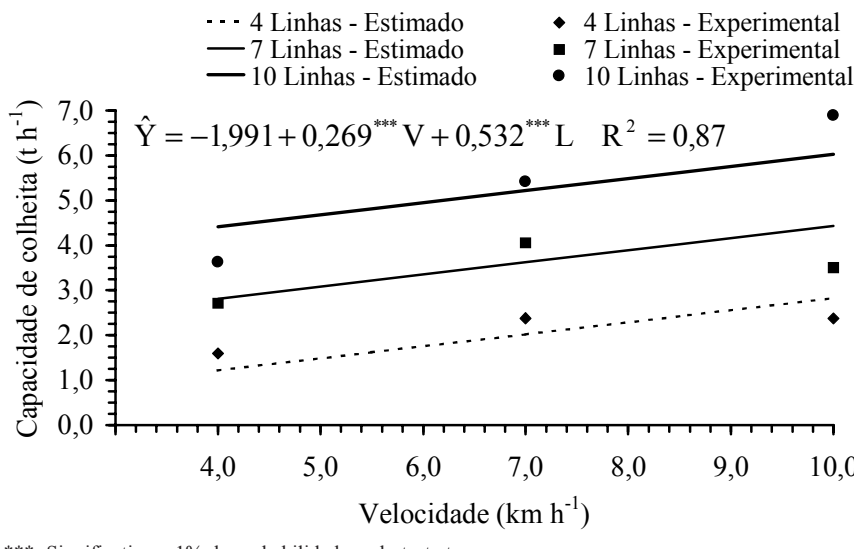

Figura 11. Estimativa da capacidade de colheita, em função da velocidade de deslocamento da máquina, para as respectivas constituições de leira, com rotações do cilindro trilhador de 420 (A) e 540 rotações $\min ^{-1}$ (B) e teor de umidade de $10,65 \%$ pois o nível aceitável de perda na colheita mecânica se encontra no intervalo de 3 a $5 \%$.

O produto com teor de umidade de $10,65 \%$, em média, apresentou a perda na plataforma de recolhimento maior que aquelas observadas nos outros mecanismos da colhedora, seguida pelas perdas no sistema de trilha e separação e no sistema de limpeza, com valores de 52,44, 41,21 e 6,35\%, respectivamente; já na colheita do feijão com teor de umidade de $14,10 \%$, houve inversão entre as perdas ocorridas na trilha e separação e na plataforma de recolhimento, cujos valores foram de 45,94 e $48,03 \%$, respectivamente, sendo que a perda na limpeza foi de $6,03 \%$.

Para o estudo do comportamento da capacidade de colheita, em função do número de linhas de feijão na leira, da velocidade de deslocamento e rotação do cilindro trilhador da máquina, foram feitos cortes nos modelos de superfície de resposta ajustados, conforme Figuras 11 e 12.

Analisando-se os resultados obtidos, verifica-se que a capacidade de colheita é diretamente proporcional à velocidade de deslocamento, ao número de linhas na leira e à rotação do cilindro trilhador. Por sua vez, os testes realizados com leiras constituídas de 10 linhas apresentaram os maiores valores de capacidade de colheita, acontecendo o mesmo para a velocidade de $10,0 \mathrm{~km} \mathrm{~h}^{-1}$ e rotação do cilindro trilhador de $540 \mathrm{~min}^{-1}$. Os melhores resultados da capacidade de colheita foram observados na colheita com teor de umidade de $14,10 \%$, atingindo $6,56 \mathrm{th}^{-1}$, enquanto com teor de umidade de $10,65 \%$, a maior capacidade de colheita foi de $6,02 \mathrm{t} \mathrm{h}^{-1}$. A diferença
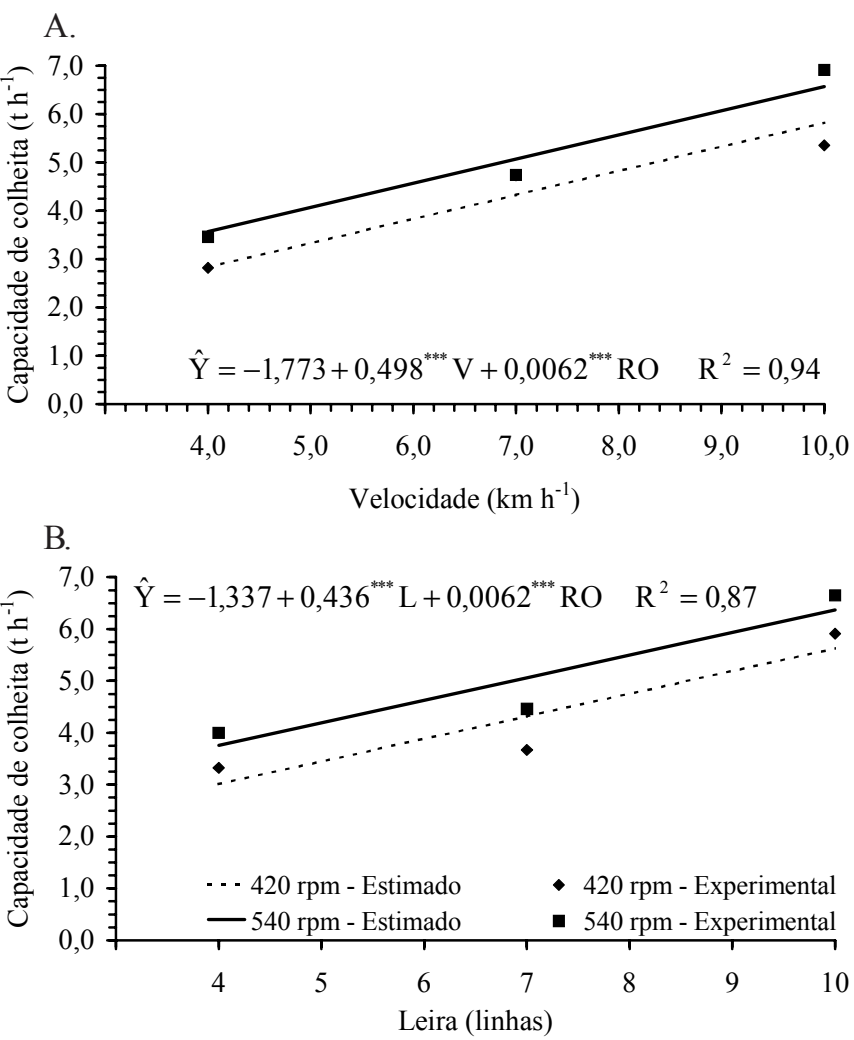

*** Significativo a $1 \%$ de probabilidade, pelo teste $\mathrm{t}$

Figura 12. Estimativa da capacidade de colheita, em função da velocidade de deslocamento da máquina $(\mathrm{A})$ e do número de linhas na leira (B), para as respectivas rotações do cilindro trilhador, com teor de umidade de $14,10 \%$ 
entre esses valores está associada à diferença de produtividade entre os dois pivôs centrais, pois a produtividade tem influência direta na taxa de alimentação da máquina.

A rotação do cilindro trilhador da máquina influenciou o aumento do resultado da capacidade de colheita porque esta foi incrementada, variando a rotação do motor do trator. Observou-se em campo que, quando trabalhando em baixa rotação na TDP e a taxa de alimentação da máquina era aumentada, ocorria ligeiro decréscimo na velocidade de deslocamento, para compensar a maior exigência de torque do cilindro trilhador.

Segundo Skromme (1977) as colhedoras com sistema de trilha em fluxo axial apresentam maior capacidade de colheita e reduzem os índices de danos mecânicos, em relação às colhedoras com o sistema de trilha com fluxo radial.

\section{CONCLUSÕES}

1. O arranquio e o enleiramento manual das plantas de feijão, quando realizados de maneira adequada, reduzem significativamente a possibilidade de perdas.

2. As leiras constituídas de 10 linhas, o teor de umidade de $14,10 \%$, a velocidade da colhedora de $4,0 \mathrm{~km} \mathrm{~h}^{-1}$ e rotação do cilindro trilhador de 420 rotações min $^{-1}$ apresentaram menores valores de perda na plataforma.

3. O teor de umidade de $10,65 \%$, a rotação do cilindro trilhador de 540 rotações $\min ^{-1}$ e o aumento da taxa de alimentação apresentaram menores valores de perda no sistema de trilha e separação.

4. A perda no sistema de limpeza da colhedora evidenciou comportamento quadrático em função da taxa de alimentação. A rotação de 420 rotações $\min ^{-1}$ apresentou menores valores de perda no sistema de limpeza, não havendo influência do teor de umidade de colheita.

5. O teor de umidade de $10,65 \%$ e o aumento da taxa de alimentação apresentaram os menores valores de perda total da colhedora, independentemente da rotação do cilindro trilhador da máquina.

6. Em média, a perda na plataforma de recolhimento atingiu os maiores valores, seguida pelas perdas no sistema de trilha e separação e no sistema de limpeza.

7. A capacidade de colheita aumentou com o aumento da taxa de alimentação e a rotação do cilindro trilhador do colhedora.

\section{AGRADECIMENTOS}

Ao Conselho Nacional de Desenvolvimento Científico e Tecnológico (CNPq), pela bolsa concedida, à Fundação de Amparo à Pesquisa do Estado de Minas Gerais (FAPEMIG) e às Indústrias Reunidas Colombo Ltda. pelo auxílio à pesquisa e suporte financeiro.

\section{LITERATURA CITADA}

Boller, W.; Klein, V.A.; Panisson, E. Perdas na colheita mecanizada de soja em função de diferentes níveis de umidade dos grãos. In: Congresso Brasileiro e Engenharia Agrícola, 27, 1998, Poços de Caldas. Resumos... Poços de Caldas: SBEA, 1998. p.310-312.

Conto, A.J.; Vieira, E.H.N.; Oliveira, E.T.; Castro, T.A.P. Aspecto técnico e econômico da colheita mecânica e manual do feijão (Phaseolus vulgaris L.). EMBRAPA-CNPAF. Goiânia, GO. 1980. 18p.

Contreras, G.A.M. Otimização de um mecanismo articulado para o levantamento de plantas e seguimento do perfil do solo em processos de colheita. Campinas, SP: UNICAMP. 1997. 90p. Tese Doutorado

Dunn, W.E.; Nave, W.R.; Butler B.J. Combine header component losses in soybeans. Transactions of the ASAE, St. Joseph, v.16, n.6, p.1032-1035, 1973.

Griffin, G.A. Combine harvesting. In: Fundamentals of Machine Operation. 4. ed. Illinois: John Deere \& Company/Malone. 1991.216p.

Mesquita, C.M.; Costa, N.P.; Maurina, A.C.; Andrade, J.G.M.; Pereira, J.E. Colheita mecânica da soja: Redução de perdas em vinte anos. Engenharia Agrícola, Jaboticabal, v.18, n.2, p.71-80, 1998.

Nave, W.R.; Tate, D.; Butler B. Combine headers for soybeans. Transactions of the ASAE, St. Joseph, v.15, n.4, p.632-635, 1972.

Portella, J. A. Perdas de trigo, de soja e de milho x umidade do grão durante a colheita mecanizada. In: Congresso Brasileiro de Engenharia Agrícola, 26, Campina Grande. Resumos... Campina Grande: SBEA, 1997. CD Rom.

Silva, C.C.; Oliveira, E.T.; Carneiro, J.E.; Aidar, H.; Fagundes, A.; Dalsenter, W.; Vanderlei, C.; Bassin, R.A.; Fonseca, J.R. Colheita mecanizada do feijão. Goiânia: EMBRAPA. 1994, 27p. Boletim de Pesquisa $\mathrm{N}^{\circ} 8$

Silva, C.C.; Bevitori, R. Colheita e beneficiamento de feijão. Informe Agropecuário: Feijão no inverno. Belo Horizonte, v.17, n.178, p.63-65, 1994.

Silva, J.S.; Queiroz, D.M. Colheita, trilha, secagem e armazenagem. In: Vieira, C.; Paula Júnior, T. J.; Borém, A. Feijão - Aspectos gerais e cultura no estado de Minas Gerais. Viçosa: Editora UFV. 1998. p.559-585.

Singh, K.N.; Singh, B. Effect of crop and machine parameters on threshing effectiveness and seed quality of soybean. Journal of Agricultural Engineering Research,. Silsoe, v.26, p.349-355, 1981.

Skromme, L. H. Progress report on twin rotor combine concept of rotary threshing and separation. In: International Grain and Forage Harvesting Conference, 1, 1977, St. Joseph. Proceeding... St. Joseph: ASAE, 1977. p.188-191 e 195.

Smith, J.A. Dry edible bean field harvesting losses. Transactions of the ASAE, St. Joseph, v.29, n.6, p.1540-1543, 1986. 